\title{
AN APPROACH TO EVALUATE THE HEAT EXCHANGER RETROFIT FOR INSTALLED INDUSTRIAL GAS TURBINES: PART I- TECHNICAL EVALUATION
}

\author{
Waleed Al-Busaidi ${ }^{1}$, Pericles Pilidis ${ }^{2}$ \\ ${ }^{1}$ Researcher in Cranfield University; School of Aerospace, Transport and Manufacturing; Bedfordshire; UK \\ ${ }^{2}$ Head of Propulsion Engineering Centre, Cranfield University, Bedfordshire, UK
}

\begin{abstract}
This paper is the first part of a two-part study aiming to introduce a new integrated approach to evaluate the techno-economic value of recuperator retrofit on existing gas turbine engines. The original gas turbines are designed for combined cycles so that the pressure ratios are moderate to secure suitable exhaust temperatures. One way to enhance the thermal efficiency of some gas turbines is by using recuperation to recover some of the exhaust heat. In this part, the developed model is described and implemented for two gas turbine engines so the obtained characteristics are evaluated against the actual data. The new approach will assist users to select the suitable gas turbine models with favorable recuperator characteristics based on a technical and economic prospective. Besides, the performance results are used to design an appropriate shell and tube heat exchanger. Moreover, a new technique has been established to define the typical heat exchanger parameters in order to ensure the highest possible improvements over the original cycles. One of the main features of this method is that it depends only on the velocity of hot and cold heat exchanger streams from which the rest of the heat exchanger design and performance characteristics were derived.
\end{abstract}

Key Words: integrated approach, techno-economic value, recuperation, shell and tube heat exchanger, velocity

\section{INTRODUCTION}

Many existing power generation installations are based on moderate pressure ratio gas turbines where the exhaust gas temperature (EGT) is greater than the compressor discharge temperature(CDT). This makes the provision of a heat transfer process attractive [1]. Besides, the low fuel consumption has been one of the critical features to select a gas turbine for power generation due to the gradual increase in the fuel cost. One way to enhance this efficiency is by using the recuperation to recover some of the exhausted heat which normally exceeds $50 \%$ of the total produced energy instead of injecting it into the atmosphere.

The main function of gas turbine heat exchangers is to enable the heat transfer from the hot stream coming fro $m$ the turbine exhaust to the cold stream which is the discharge compressor air. The actual amount of heat transfer between the recuperator streams can be determined by the following equation.

$$
Q_{a c t}=W_{h} C_{P, h}\left(T_{h 1}-T_{h 2}\right)=W_{c} C_{P, C}\left(T_{c 2}-T_{c 1}\right)
$$

The desired characteristics of a heat exchanger are: high effectiveness, low pressure drop, low manufacturing and operating costs and low physical weight and size. The importance of each of these features depends on the type of application [2]. Unfortunately, there is a conflict between some of these design characteristics so to design a heat exchanger with a higher effectiveness, a larger recuperator size is required which should be considered in terms of the available space and maximum allowed weight in some applications. Furthermore, the price of the heat exchanger is strongly influenced by its size so as recuperator size increases, the price will also increase. Consequently, the selected features of the heat exchanger have to be optimized and a compromise has to be performed to select the appropriate characteristics based on the application require ments.

Unfortunately, there is no available systematic approach in the open literature to define the optimum cycle parameters and typical heat exchanger characteristics for higher technoeconomic value. Hence, this study aims to introduce a new approach to determine the optimum heat exchanger characteristics in order to attain the highest possible technical and economical values. One of the unique features of the developed method is that that it basically depends on the flow velocity to derive the rest of parameters. This model has been implemented with two installed gas turbine models and an optimization process is conducted to select the design parameters of the heat exchanger.

This paper is organized into three main sections. The first part presents some backgrounds for the developed method followed by the detailed description of the used methodology and empirical correlations. The second part demonstrates the obtained heat exchanger and overall cycle characteristics using the derived approach for both gas turbines. Finally, a sensitivity study is performed to evaluate 
the suction parameters effects on the overall recuperative gas turbine cycle.

\section{HEAT EXCHANGER EVELUATION METHODOLOGY}

This part of the study describes the technical evaluation of the heat exchanger features for gas turbine retrofit. This example will be a useful illustration of how to optimize recuperator characteristics for better cycle performance.

The performance of the gas turbines is simulated and the isentropic efficiencies, pressure losses and bleed air are assumed in order to match the performance of the simulated models with the original specifications provided by the supplier. The calculated discharge compressor conditions and the turbine exhaust parameters are used as input features of both cold and hot streams respectively.

The designed heat exchanger is from shell and tube type which is used widely in process industry. In general, the high-pressure stream is typically directed through the tubes while the other stream flows in the space between the tubes and the outer shell. The tube geometry parameters are assumed at the beginning and then modified to obtain the allowed pressure drop in the cold side. Besides, the required duty is calculated using both Log Mean Temperature Difference and Number of Transfer Units methods. The overall heat transfer coefficient (U) is assumed and it is iterated at the end until both values are equal.

The inside heat transfer coefficient is assumed and then it will be calculated based on Reynolds number and tube geometry. The assumed value is iterated to be equal to the final calculated coefficient. Moreover, the shell geometry dimensions are specified based on the recommended values of the shell design parameters and the allowed pressure drop in the hot side.There are different methods that have been developed to calculate the heat transfer coefficient and pressure drop of shell side, the Bell-Delaware method has been used in this paper.

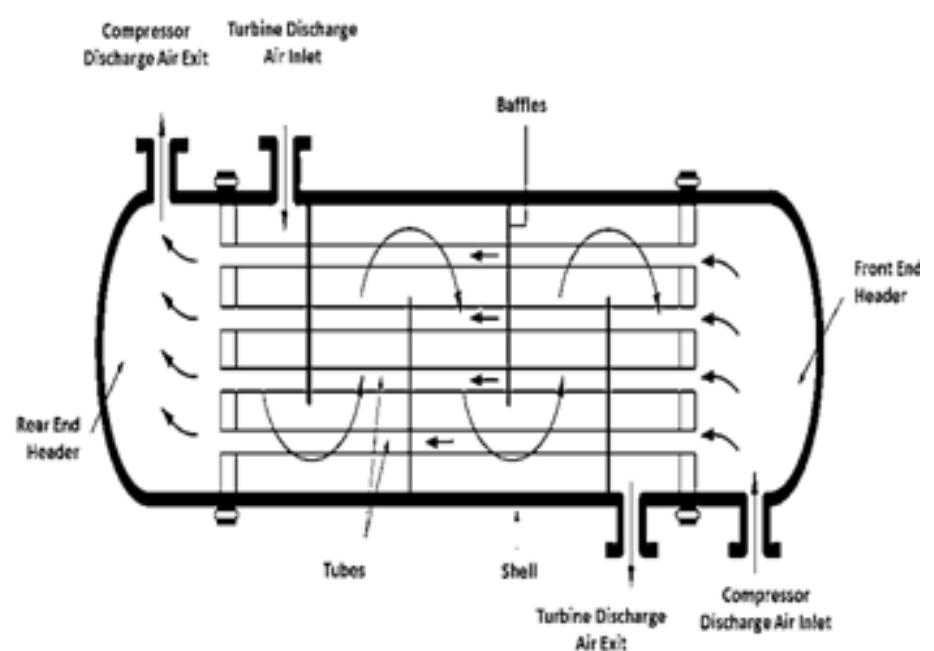

Figure 1: Basic Component of Shell and Tube Heat Exchanger
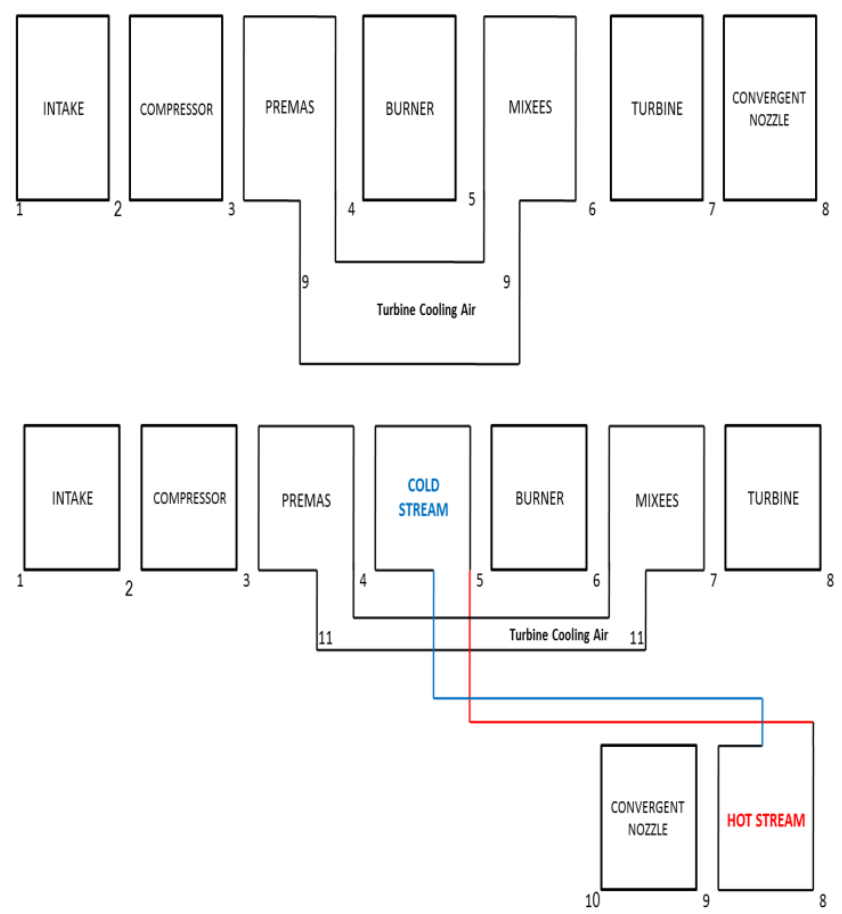

Figure 2: Basic Component of Simu lated Simple and Recuperative Engine Cycles
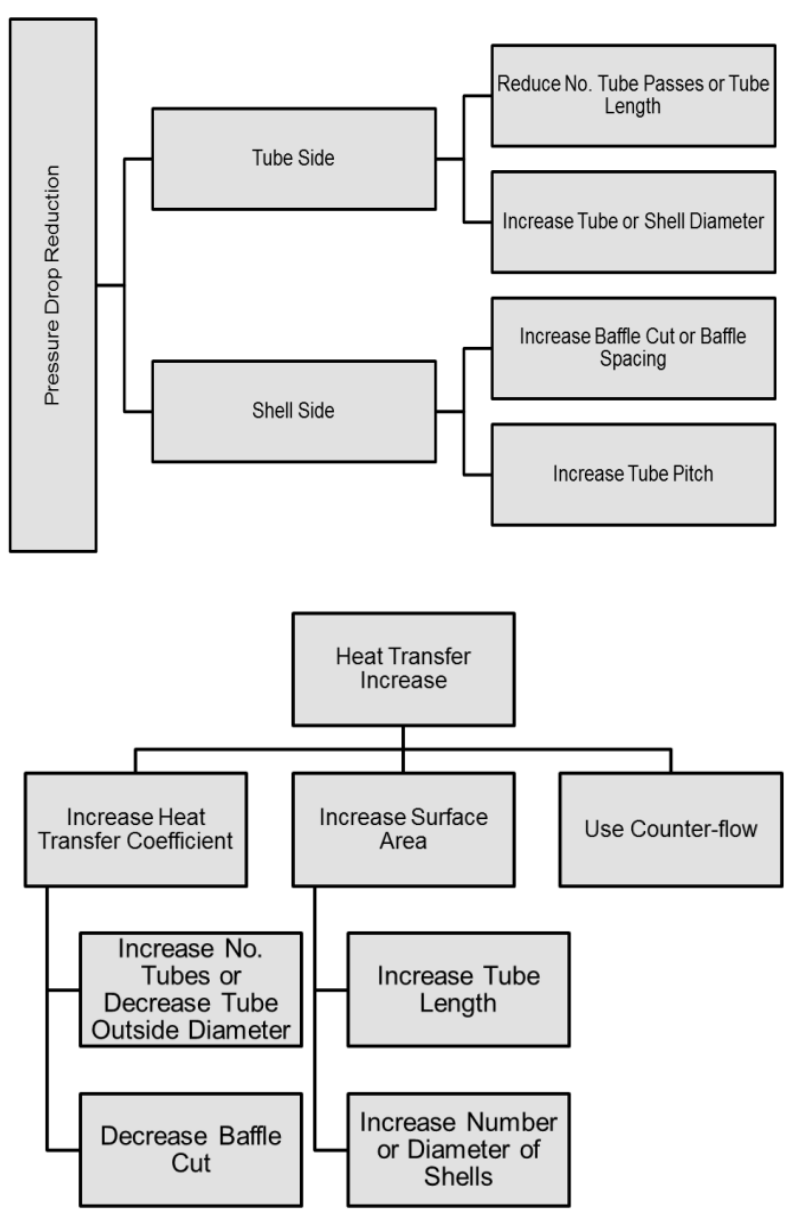

Figure 3: A Strategy to Choose the Pressure Drop and Heat Transfer 


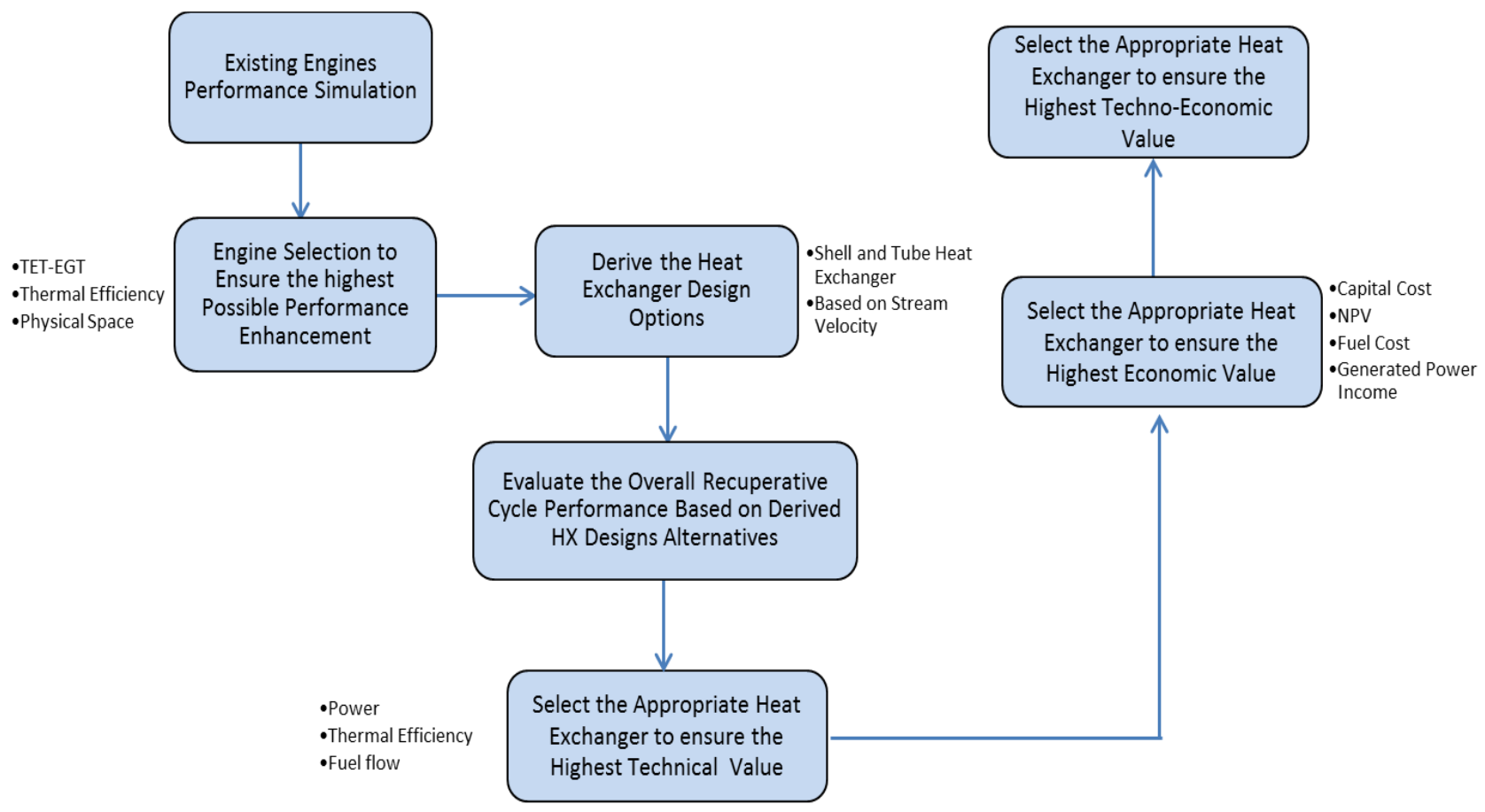

Figure 4: Flow Diagram of the Developed Approach

The size and weight of the recuperator are calculated based on the selected design parameters which can be iterated to obtain the allowed recuperator size and weight when the space and weight are critical.

In general, the geometrical parameters of the recuperator have been selected to satisfy the required duty and in order to meet the expected effectiveness and pressure drops of both sides. Figure 3 illustrates the design parameters that can be adjusted to control the required heat transfer duty and pressure drops. This is used to optimize the optimal recuperator characteristics according to the derived features and the impact on the overall recuperative cycle.

An important feature of the developed methodology is its dependency on the inlet flow velocity of the recuperator to obtain the geometrical features of the installed heat exchanger and the overall performance parameters of the recuperative cycle.

$$
\eta, P S, P, N P V, \Delta p, w=f\left(v_{1 c}, v_{1 h}\right)
$$

In this paper, a technical evaluation is conducted to decide the typical heat exchanger features which will be assessed economically in the second part of this study

\section{DEVELOPED APPROACHDESCRIPTION}

\subsection{Engine Selection Technique}

When there are several existing gas turbines models operating in the field, the right selection for the engine is essential to achieve the highest possible improvement in the performance. In this study, three main criteria will be used to evalute the simple cycle gas turbines performance which are:
- Difference between the compressor discharge temperature (CDT) and exhaust gas temperature (EGT)

- Available installation space.

- Thermal efficiency of orig inal operating gas tubine cycle.

The thermla efficiency of gas turbine cycle can be calculated as a function of the useful work and the input heat to the burner.

$$
\eta=\frac{\left[\dot{m} C_{p}(\Delta T)\right]_{T u}-\left[\dot{m} C_{p}(\Delta T)\right]_{C o}}{\left[\dot{m} C_{p}(\Delta T)\right]_{C C}}=
$$

Thus, the higher efficiency can be achieved by reducing the amount of burned fuel in the combustor. This can be achieved by raising the compressor discharge temperature prior the burner using the exhuased air fro $m$ the turbine.

$$
Q_{\text {act }}=\varepsilon \times Q_{\text {Max }}
$$

So, as the temperature difference between the turbine exhuast and the compressor dicsharge increases, the maximum amount of transferred heat $\left(Q_{\operatorname{Max}}\right)$ will go up uielding to lower required fuel flow.

Another factor which affects the actual heat transfer rate in the recuperator is the effectiveness. However, the higher effectiveness requires larger heat transfer area which obviously yields to larger heat exchanger size as will be investigated further in this study. 


\subsection{Determination of Gas Properties at Recuperator}

\section{Sides}

The outlet pressure and temperature from the shell and tube can be determined by calculation from:

$$
\begin{gathered}
P_{2}=P_{1} \times\left[1-\frac{\Delta P(\%)}{100}\right] \\
T_{\text {cold ,out }}=(1-\varepsilon) \times T_{\text {cold ,in }}+\varepsilon \cdot T_{\text {hot, in }}
\end{gathered}
$$

The dynamic viscosity can be calculated as a function of the average temperature only using a correlation published by Crane Company [3]. This equation is used for some common gases and it was derived based on assumption that the impact of pressure is minor ( $\leq 10 \%$ for the gases) and can be neglected.

$$
\mu\left(\frac{K g}{m . s}\right)=\frac{1.5105 \times 10^{-6} \times T_{a v g}^{1.5}}{T_{a v g}+120}
$$

Where: $T_{a v g}$ is the average temperature in Kelvin $\left({ }^{\circ} \mathrm{k}\right)$

The thermal conductivity $(\mathrm{K})$ can be determined for hot and cold streams using the correlation given by PasterAguilar study [4]. This also has been developed assuming that the thermal conductivity is a function of the average temperature only.

$$
\begin{array}{rl}
K\left(\frac{W}{m \cdot K}\right)=1.52 & 07 \times 10^{-11} \times T_{\text {avg }}{ }^{3}-4.8574 \\
& \times 10^{-8} \times T_{\text {avg }}{ }^{2}+1.0184 \\
& \times 10^{-4} \times T_{\text {avg }}-3.9333 \\
& \times 10^{-4}
\end{array}
$$

To calculate the specific heat, the corre lation given by Ieradi [5] is used. This equation has been derived experimentally by plotting the variation of specific heat $\left(C_{p}\right)$ against temperatures which has been done by. However, this formula determines the specific heat $\left(C_{p}\right)$ in terms of the average temperature only without a considering of the fuel flow effect.

$$
\begin{aligned}
C_{p}\left(\frac{J}{K g \cdot K}\right)=1 . & 9327 \times 10^{-10} \times T_{a v g}{ }^{4}-7.9999 \\
& \times 10^{-7} \times T_{\text {avg }}{ }^{3}+1.1407 \\
& \times 10^{-3} \times T_{\text {avg }}{ }^{2}-4.4890 \\
& \times 10^{-1} \times T_{\text {avg }}+1.0575 \times 10^{3}
\end{aligned}
$$

- $\quad$ Tube length $\left(l_{t}\right)$

The inlet tube diameter $\left(d_{t}\right)$ can be calculated based on the specified tube outside diameter and its wall thickness. Besides, the LMTD method is used to determine the required tube area corresponding to the assumed overall heat transfer coefficient $(U)$ by applying the following equation.

$$
A_{t}=\frac{Q_{\text {actual }}}{U \times L M T D}=\frac{Q_{\text {actual }}}{U \times\left[\frac{\left(T_{1}-t_{2}\right)-\left(T_{2}-t_{1}\right)}{\ln \left[\frac{\left(T_{1}-t_{2}\right)}{\left(T_{2}-t_{1}\right)}\right]}\right]}
$$

For higher effectiveness, the direction of flow is assumed to be counter-flow so the correction value $(\mathrm{F})$ is substituted by one. Then, the number of required tubes can be calculated using the formula below.

$$
N_{t}=\frac{A_{t}}{\pi \times D_{t} \times l_{t}}
$$

The cold air is coming from the compressor at high pressure and velocity. So, it is necessary to ensure that the high velocity will not cause a high pressure drop within the tubes. The velocity throughout the tubes can be determined from the obtained number of tubes per pass and by knowing the total inlet flow rate of the discharge compressor air.

Numerically, the Darcy friction factor can be calculated directly using Swamee and Jain's equation [6] without iteration.

$$
f=0.25\left[\log \left(\frac{\varepsilon / \mathrm{d}_{\mathrm{t}}}{3.7}+\frac{5.74}{R e_{t}{ }^{0.9}}\right)\right]^{-2}
$$

The tubes are assumed to be straight so that the flow is considered as fully developed. Thus, the frictional pressure drop $\left(\Delta p_{f}\right)$ is derived from the equation of the fanning friction factor. Besides, the combined header and tube entrance losses $\left(\Delta p_{\text {ent }}\right)$ can be estimated using the velocity inside the tubes $\left(V_{t}\right)$. So, the total pressure drop of tube side $\left(\Delta p_{t}\right)$ is calculated from:

$$
\Delta p_{t}=4 \times f\left(\frac{l_{t}}{\mathrm{~d}_{\mathrm{t}}}\right) \times\left(\frac{\rho \times V_{t}^{2}}{2}\right)+3\left(\frac{\rho \times V_{t}^{2}}{2}\right) \times n
$$

\subsection{Heat Exchanger Design Theory}

Four input parameters can be selected to modify the tube geometry; these are:

- Tube outside diameter $\left(D_{t}\right)$

- Tube wall thickness $\left(t_{t}\right)$

- Tube roughness 


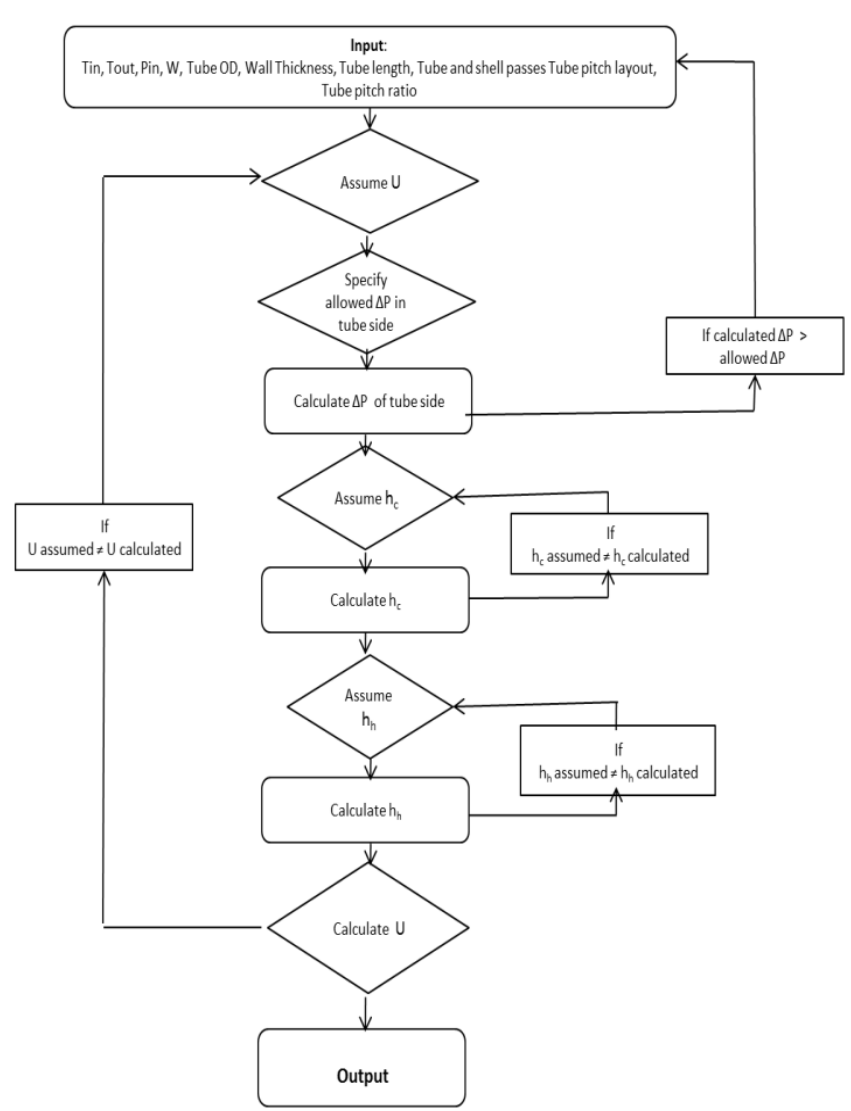

Figure 5: Developed Methodology for Heat Exchanger Design

The flow of the cold compressor discharge air is turbulent and the cross sectional area of the tubes is usually not large enough to allow laminar flow. So, the inside heat transfer coefficient for turbulent flow can be determined by equation (14).

$$
h_{i}=a\left(\frac{k_{t}}{\mathrm{~d}_{\mathrm{t}}}\right) \times R e^{0.8} \times \operatorname{Pr}^{1 / 3}
$$

Different sources offer various values for the formula coefficient (a) ranging from 0.019 to 0.027 so the average value is taken in this study.

In order to obtain realistic results, the outside heat transfer coefficient $\left(h_{s}\right)$ will be calculated using Bell-Delaware method [7]. Despite its relative complexity, this technique has been proven to provide more accurate and reliable estimation and it is used frequently in the industry today. Based on this method, the outside heat transfer coefficient $\left(h_{s}\right)$ can be calculated using the following equation:

$$
h_{s}=h_{i} \times J_{c} \times J_{l} \times J_{b} \times J_{s} \times J_{r}
$$

The ideal heat transfer coefficient $\left(h_{i}\right)$ is determined by applying correlation (16).

$$
\begin{gathered}
h_{i}=\left[a_{1}\left(\frac{1.33}{p_{t} / \mathrm{D}_{\mathrm{t}}}\right)^{\frac{a_{3}}{1+0.14(\operatorname{Res})^{a_{4}}}} \times\left(R e_{s}\right)^{a_{2}}\right] \times C_{p s} \times\left[\frac{\dot{m}_{s}}{S_{m}}\right] \\
\times\left[\frac{K_{s}}{C_{p s} \mu_{s}}\right]^{2 / 3}
\end{gathered}
$$

The segmental baffle window correction factor $\left(J_{c}\right)$ and baffle leakage correction factor $\left.J_{l}\right)$ is obtained from equations (17) and (18).

$$
\begin{gathered}
J_{c}=0.55+\times \frac{0.72}{\pi}\left[\pi+2\left(\frac{D_{s}-2 L_{c}}{D_{o t l}}\right) \sin \left(\cos ^{-1}\left(\frac{D_{s}-2 L_{c}}{D_{o t l}}\right)\right)\right. \\
\left.-2 \cos ^{-1}\left(\frac{D_{s}-2 L_{c}}{D_{o t l}}\right)\right] \\
J_{l}=0.44\left(1-\frac{S_{s b}}{S_{s b}+} S_{t b}\right) \\
+[1 \\
\left.-0.44\left(1-\frac{S_{s b}}{S_{s b}+S_{t b}}\right)\right] \exp (-2.2 \\
\left.\times \frac{S_{s b}+S_{t b}}{S_{m}}\right)
\end{gathered}
$$

The bypass correction factor $\left(J_{b}\right)$ is determined based on the ratio of sealing strips to tubes crossings $\left(r_{s s}\right)$ as following:

If $r_{s s}<0.5$

$$
\begin{aligned}
J_{b}=\exp \left[-C_{b h}\right. & \times \frac{l_{s} \times\left[\left(D_{s}-D_{o t l}\right)+0.5 D_{t} \times N_{p}\right]}{S_{m}} \\
& \left.\times\left(1-\sqrt[3]{2 \times r_{s s}}\right)\right]
\end{aligned}
$$

If $r_{S S} \geq 0.5$

$$
J_{b}=1
$$

The correction factor of unequal baffle spacing $\left(\mathrm{J}_{\mathrm{s}}\right)$ is calculated using below formula assuming an equal spacing for the in let and outlet baffles $\left(L_{i}=L_{o}\right)$

$$
J_{s}=\frac{\left(N_{b}-1\right)+\left(L_{i}^{*}\right)^{1-n}+\left(L_{o}^{*}\right)^{1-n}}{\left(N_{b}-1\right)+L_{i}^{*}+L_{o}^{*}}
$$

Where:

$n:$ Formula exponent $=\left\{\begin{array}{cc}\frac{1}{3} \text { for } & R e_{s}<100 \\ \frac{3}{5} \text { for } & R e_{s} \geq 100\end{array}\right\}$

The correction factor of adverse temperature gradient $\left(\mathrm{J}_{\mathrm{r}}\right)$ is based on the shell flow Reynolds number $\left(R e_{s}\right)$.

So, if $R e_{s}<20$ 


$$
\begin{aligned}
& J_{r}=\left(J_{r}\right)_{r} \\
& =\left\{\frac{10}{\left.\left(\frac{D_{s}-2 L_{c}}{X_{l}}\right)+\frac{0.8}{X_{l}}\left(L_{c}-\frac{D_{s}-\left(D_{\text {otl }}-D_{t}\right)}{2}\right)\right] \times\left(N_{b}+1\right)}\right\}^{0.18}
\end{aligned}
$$

If $20 \leq R e_{s} \leq 100$

$$
J_{r}=\left(J_{r}\right)_{r}+\left(\frac{20-R e_{s}}{80}\right) \times\left[\left(J_{r}\right)_{r}-1\right]
$$

If $R e_{s}>100$

$$
J_{r}=1
$$

The shell-side pressure drop $\left(\Delta P_{S}\right)$ is determined by summing the pressure drops of three regions in the shell which are the interior cross section $\left(\Delta P_{c}\right)$, shell window $\left(\Delta P_{w}\right)$ and end zones $\left(\Delta P_{e}\right)$.

$$
\Delta P_{s}=\Delta P_{c}+\Delta P_{w}+\Delta P_{e}
$$

\section{EXISTING GAS TURBINE MODELS EVALUATION: CASE STUDY (1)}

Five different models of gas turbines have been analyzed and table 1 shows their calculated performance parameters with less than $1 \%$ average deviation of each engine from the OEM specifications. These engines will be called by: W6B, W6FA, W9E, W7FA and W9FA respectively.

Figure 6 illustrates the difference between EGT and CDT of these engines and how it varies with power setting at ISO conditions ( $1 \mathrm{~atm}, 15^{\circ} \mathrm{C}$ ). This is an important factor that indicates the usefulness of the retrofit of a heat exchanger. As this temperature difference increases, the amount of transferred heat will increase with a consequent benefit on thermal efficiency.

On the other hand, the negative value at low part load operation would be detrimental to the overall efficiency of the recuperative cycle. Based on this result, this kind of cycles is not useful at less than $50 \%$ of the engine full load capability.

When space for the heat exchanger installation is limited, the engine with the lowest mass flow should be selected to

\begin{tabular}{|c|c|c|}
\hline Model & Parameter & Value \\
\hline \multirow{6}{*}{ 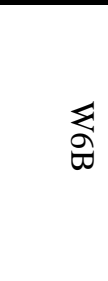 } & ISO Rating Power (MW) & 42.1 \\
\hline & Pressure Ratio & 12.2 \\
\hline & Thermal Efficiency (\%) & 32.64 \\
\hline & Exhaust Temperature $\left({ }^{\circ} \mathrm{C}\right)$ & 561 \\
\hline & Flow Rate $(\mathrm{kg} / \mathrm{s})$ & 141.1 \\
\hline & Firing Temperature $\left({ }^{\circ} \mathrm{C}\right)$ & 1140 \\
\hline \multirow{6}{*}{$\begin{array}{l}\sum \\
\text { T) } \\
>\end{array}$} & ISO Rating Power (MW) & 70 \\
\hline & Pressure Ratio & 14.9 \\
\hline & Thermal Efficiency (\%) & 34.86 \\
\hline & Exhaust Temperature $\left({ }^{\circ} \mathrm{C}\right)$ & 600.53 \\
\hline & Flow Rate (kg/s ) & 196 \\
\hline & Firing Temperature $\left({ }^{\circ} \mathrm{C}\right)$ & 1288 \\
\hline \multirow{6}{*}{$\underset{\mid(1)}{\mid}$} & ISO Rating Power (MW) & 126 \\
\hline & Pressure Ratio & 12.6 \\
\hline & Thermal Efficiency (\%) & 33.68 \\
\hline & Exhaust Temperature $\left({ }^{\circ} \mathrm{C}\right)$ & 548.44 \\
\hline & Flow Rate $(\mathrm{kg} / \mathrm{s})$ & 418 \\
\hline & Firing Temperature $\left({ }^{\circ} \mathrm{C}\right)$ & 1124 \\
\hline \multirow{6}{*}{$\begin{array}{l}\sum \\
\text { T1 } \\
>\end{array}$} & ISO Rating Power (MW) & 168 \\
\hline & Pressure Ratio & 14.8 \\
\hline & Thermal Efficiency (\%) & 36.89 \\
\hline & Exhaust Temperature $\left({ }^{\circ} \mathrm{C}\right)$ & 596.22 \\
\hline & Flow Rate (kg/s ) & 432 \\
\hline & Firing Temperature $\left({ }^{\circ} \mathrm{C}\right)$ & 1288 \\
\hline \multirow{5}{*}{\begin{tabular}{l}
$\sum$ \\
\} $\\
{>} \\
{>}$ & ISO Rating Power (MW) & 227 \\
\hline & Pressure Ratio & 15 \\
\hline & Exhaust Temperature $\left({ }^{\circ} \mathrm{C}\right)$ & 598.60 \\
\hline & Mass Flow (kg/s) & 602 \\
\hline & Firing Temperature $\left({ }^{\circ} \mathrm{C}\right)$ & 1288 \\
\hline
\end{tabular}}
\end{tabular}
apply the recuperation retrofit. Coincidently, moderate pressure ratio gas turbines also exh ibit high specific power.
Table 1: Specifications of the Modelled Gas Turbines at ISO Conditions and Design Point Operation

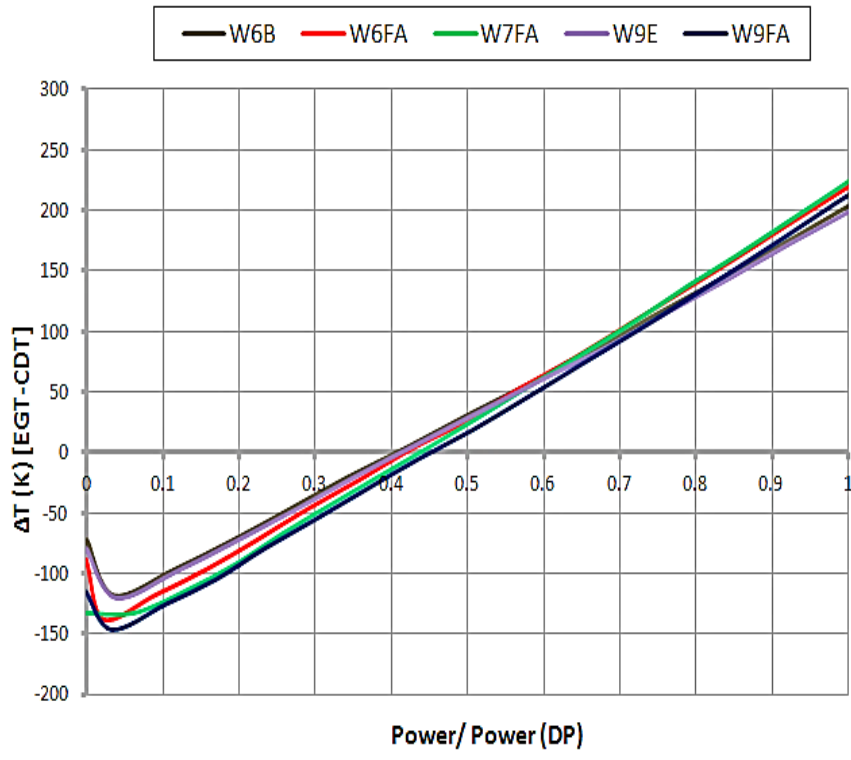

Figure 6: Predicted Temperature Difference of Simu lated Simple Cycle Gas Turbine Models at ISO Conditions 


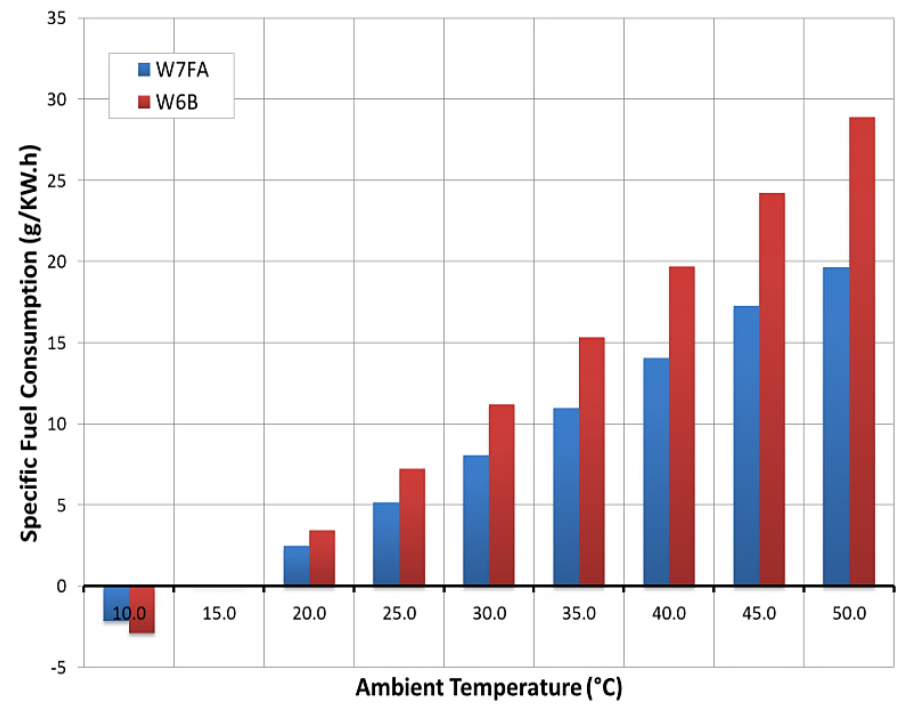

Figure 7: Deviation of Specific Fuel Consumption from ISO Fuel consumption

Heat exchangers are subjected to high thermal stresses especially during start up. So these cycles are not recommended for applications where the frequent starts are required such as peak load electricity generation [8].So, two hypothetical industrial gas turbines have been selected to apply the recuperation retrofit: the W6B and W7FA from Table 1.

Figure 7 illustrates the specific fuel consumption of the simulated engines at various operating temperature. It is interesting to observe that when the high ambient temperatures of the operating environ ment are dominant, the recuperative cycle is expected to be a good solution to recover some of the wasted heat to reduce the high fuel consumption at high ambient temperatures.

\section{NEW METHOD VALIDATION: CASE STUDY}

Two single shaft heavy duty gas turbine models have been used to evaluate the derived method. These engines are selected based on the conducted optimization in the previous section. The obtained performance parameters of the simple cycle are compared with the measured data as shown in table 2. The conducted compression revealed a good matching with the actual parameters with the maximum uncertainty of about \pm 2.3 in the exhaust temperature of the frame $6 \mathrm{~B}$ engine. This percentage is acceptable since it is still below the maximu mallowed deviation.

The performance results obtained from the simple cycle simulation are used to determine the inlet conditions of both recuperator streams as indicated in table 3. The terms W6BRC and W7FARC donate the recuperative cycle of the frames $6 \mathrm{~B}$ and 7FA engines respectively. The stated effectiveness and pressure drop values are for the proposed design by the manufacture which will be evaluated and compared with the other design options.
Table 2: Co mparis on between Predicted and Measured Gas Turbine Cycle Parameters

\begin{tabular}{|c|c|c|c|c|}
\hline Model & Parameter & $\begin{array}{l}\text { Measure } \\
\quad d\end{array}$ & $\begin{array}{l}\text { Predicte } \\
\quad \mathrm{d}\end{array}$ & $\begin{array}{c}\text { Relative- } \\
\text { Differences } \\
\%\end{array}$ \\
\hline \multirow{6}{*}{ 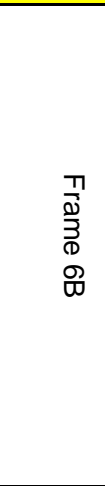 } & $\begin{array}{l}\text { ISO Rating Pow er } \\
\text { (MW) }\end{array}$ & 42.1 & 42.1 & 0 \\
\hline & Pressure Ratio & 12.2 & 12.2 & 0 \\
\hline & $\begin{array}{l}\text { Thermal Efficiency } \\
(\%)\end{array}$ & 32.1 & 32.64 & 1.68 \\
\hline & $\begin{array}{l}\text { Exhaust } \\
\text { Temperature }\left({ }^{\circ} \mathrm{C}\right)\end{array}$ & 548 & 561 & 2.3 \\
\hline & Flow Rate $(\mathrm{kg} / \mathrm{s}$ ) & 141.1 & 141.1 & 0 \\
\hline & $\begin{array}{l}\text { Firing } \\
\text { Temperature }(\stackrel{\circ}{ } \mathrm{C})\end{array}$ & 1140 & 1140 & 0 \\
\hline \multirow{6}{*}{ 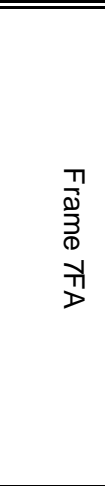 } & $\begin{array}{l}\text { ISO Rating Pow er } \\
\text { (MW) }\end{array}$ & 168 & 168 & 0 \\
\hline & Pressure Ratio & 14.8 & 14.8 & 0 \\
\hline & $\begin{array}{l}\text { Thermal Efficiency } \\
(\%)\end{array}$ & 36.2 & 36.89 & 1.9 \\
\hline & $\begin{array}{l}\text { Exhaust } \\
\text { Temperature (C) }\end{array}$ & 594 & 596.22 & 0.4 \\
\hline & Flow Rate $(\mathrm{Kg} / \mathrm{s})$ & 432 & 432 & 0 \\
\hline & $\begin{array}{l}\text { Firing } \\
\text { Temperature (C) }\end{array}$ & 1288 & 1288 & 0 \\
\hline
\end{tabular}

Table 3: Inlet and Outlet Conditions of Recuperator Streams

\begin{tabular}{c|c|c|c|c}
\multirow{2}{*}{ HX Side } & \multicolumn{2}{|c|}{ W6BRC } & \multicolumn{2}{c}{ W7FARC } \\
\cline { 2 - 5 } & Cold & Hot & Cold & Hot \\
\hline \multirow{2}{*}{$\begin{array}{c}\text { Inlet temperature } \\
\left({ }^{\circ} \mathrm{k}\right)\end{array}$} & 620 & 834 & 646 & 873 \\
$\begin{array}{c}\text { Inlet Pressure } \\
\text { (kpa) }\end{array}$ & 1223 & 103 & 1492 & 103 \\
$\begin{array}{c}\text { Mass Flow (kg/s) } \\
\text { Proposed }\end{array}$ & 130 & 143 & 386 & 440 \\
$\begin{array}{c}\text { Pressure Drop by } \\
\text { OEM (kpa) }\end{array}$ & 18 & 2.33 & 22.38 & 2.33 \\
$\begin{array}{c}\text { ProposedEffectiv } \\
\text { eness by OEM } \\
(\%)\end{array}$ & 83 & 83 & 83 & 83 \\
\hline
\end{tabular}

This study is focusing on the industrial heat exchangers which can be classified according to several criteria including: construction, surface compactness, flow arrangements, number of passes, fluids phase and heat transfer mechanism. In such applications, the high gas turbine efficiency is the primary objective. Additionally, the pressure ratios and mass flows of the gas turbines are relatively high. 
So, the recuperative type of heat exchangers will be used here to carry out the required heat transfer process. The shell and tube heat exchanger with a counter-flow arrangement will be considered here since it is the most effective among the other types. The design methodology is set based on some stated assumptions which are.

- Steady state only will be considered in this study.

- Recuperator is insulated from its surroundings so heat losses to or from the surroundings are negligible.

- No phase change - all fluids remain in gas phase.

- Constant fluids properties and heat transfer coefficients

- Inlet velocity and temperature of each stream are uniform over the flow cross section.

- Mass flow of each stream is assumed to be uniformly distributed throughout the recuperator.

The flow velocity has a significant impact on the performance characteristics of the heat exchanger and overall cycle. Hence it has been used the key design criterion to select the recuperator design features. The dependence on the inlet flow velocity makes this methodology quite unique and simple to follow by the user. For simplicity, the design process will be carried assuming an equal flow velocity of both streams. Figure 8 illustrates the flow velocity influences on the heat transfer coefficient and pressure drop of tube-side. It is clear that the tube heat transfer coefficient is varying with approximately 0.8 power of cold flow velocity, whereas the tube side pressure drop varies with the flow velocity square.

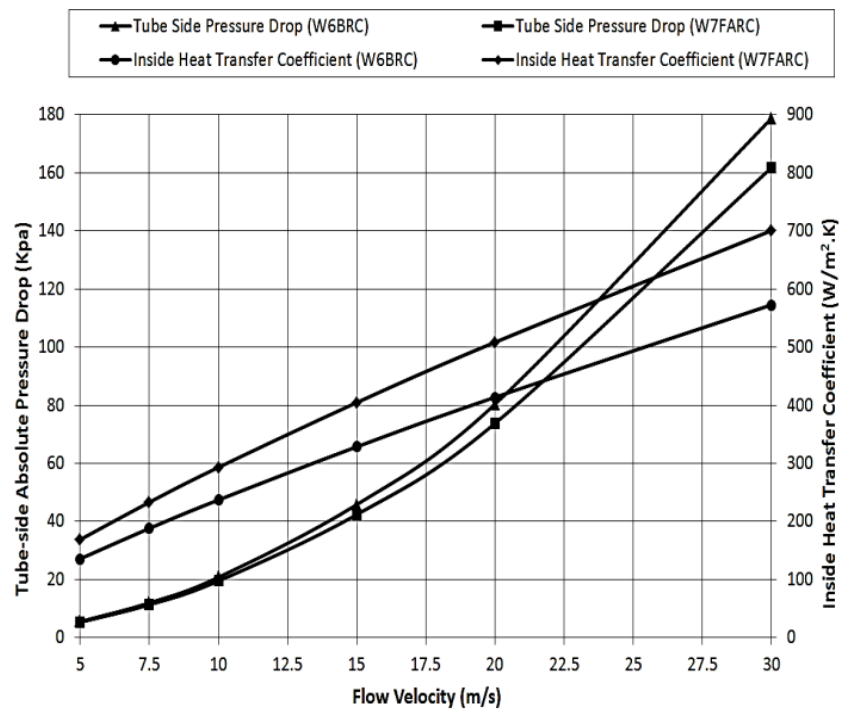

Figure 8: Flow Velocity Effect on Heat Transfer Coefficient and Pressure Drop of Tube-Side

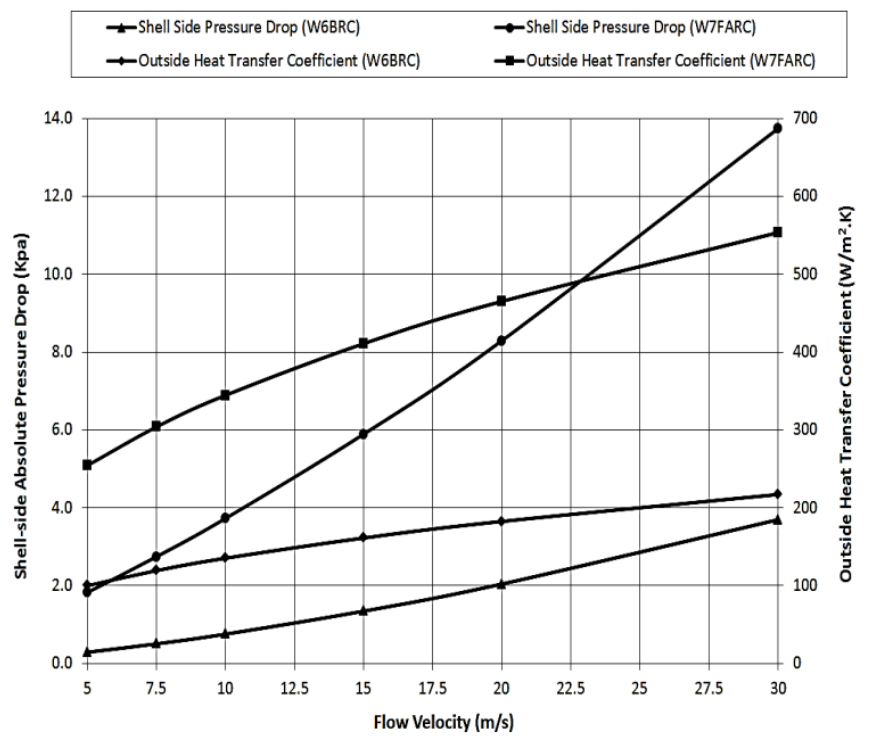

The shell heat transfer coefficient increases with flow velocity but with less sensitivity compared with that of tube side (figure 9). Moreover, the increase in the inside and outside heat transfer coefficients will enhance heat transfer which will lead to a lower heat transfer area.

To allow for the flow velocity rise, the flow rate per tube should be increased which can be achieved by reducing the number of tubes and heat transfer area. Consequently, the heat exchanger size is reduced with higher flow velocity. However high flow velocity results in increased the pressure drop; this is increasing faster than the heat transfer coefficient. Thus, the rise in the overall pressure drops of both sides is greater than the rise in heat transfer coefficient. Additionally, with low flow velocity, the increase in heat exchanger size and its heat transfer area allows for higher amount of heat transfer from the hot stream to cold stream. Hence the actual heat transfer will increase and the recuperator effectiveness will be higher as shown in figures 10 and 11 .

When the gas flows through the heat exchanger, the gas velocity induces a fluid friction which leads to reduce the gas pressure. As, the value of pressure drop increases, more power will be required to move the fluid which will reduce gas turbine power the thermal efficiency. At the same flow velocity of both recuperator streams, the absolute pressure drop in cold side is significantly greater than that of hot side due to the higher inlet pressure of the cold stream. However, the fractional pressure drop of both stream were relatively closer as observed in figure 10 wherethe dotted line indicates the estimated physical size of the proposed design by the manufacture.

Although, the high flow velocity helps to reduce the recuperator size, the resulting pressure drops will cause a greater reduction in power output and thermal efficiency. 


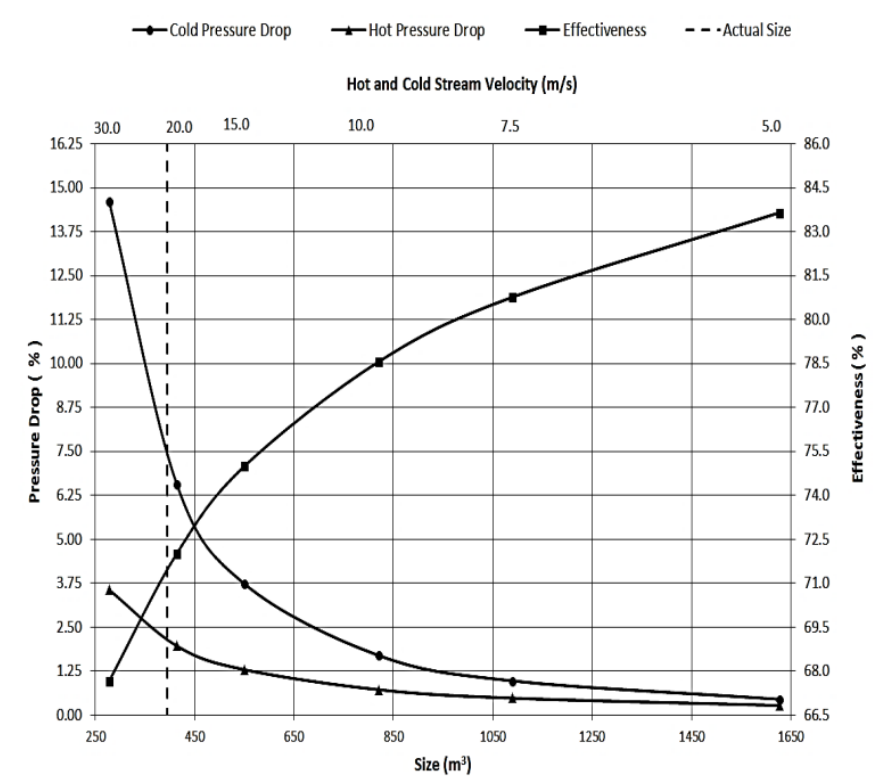

Figure 10: Influence of Recuperator Size on the Effectiveness and Pressure Drop of W6BRC

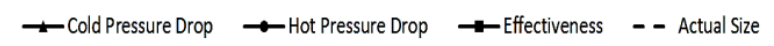
Hot and Cold Stream Velocity $(\mathrm{m} / \mathrm{s})$

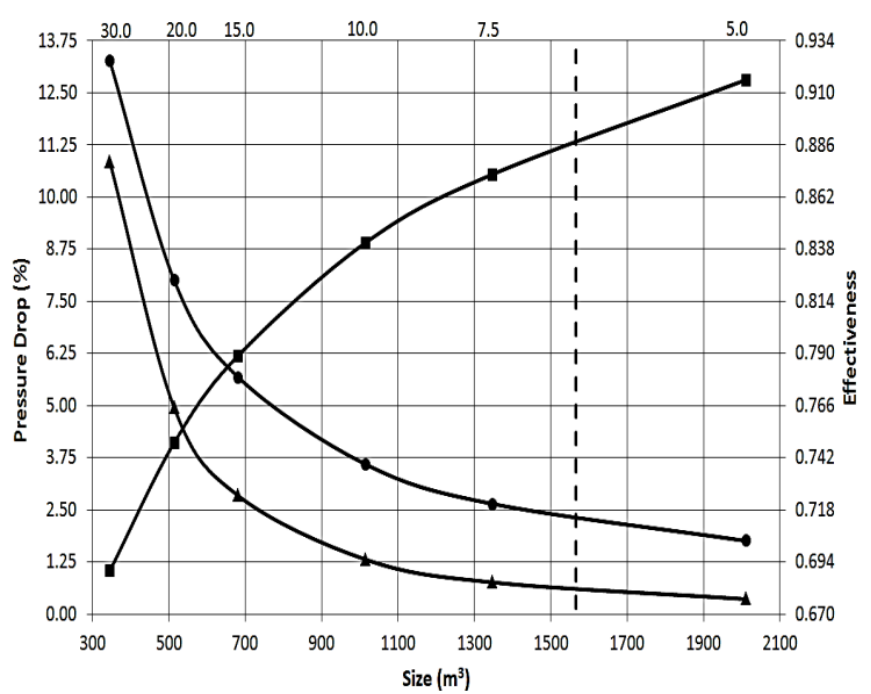

Figure 11: Influence of Recuperator Size on the Effectiveness and Pressure Drop of W7FARC

Considering the recuperator effectiveness, a large recuperator offers increased heat transfer area; hence the actual heat transfer rate and the recuperator effectiveness will increase. Moreover, the recuperator size is increasing as the flow velocity reduces. For example: the recuperator size has increased by $39 \%$ over the actual size when the flow velocity of both streams reaches $15 \mathrm{~m} / \mathrm{s}$ comparing with the size increase of $107.7 \%$ at $10 \mathrm{~m} / \mathrm{s}$ flow velocity.

Figure 11 indicates that the actual size of W7FARC heat exchanger at the design point is located in the large size region. This is needed to avoid the consequential high pressure drop at the small size region of the curve. When the flow velocity is reduced to $5 \mathrm{~m} / \mathrm{s}$, the recuperator size increases by $28.4 \%$ with pressure drops reached to $1.76 \%$ and $0.358 \%$ of the hot and cold sides respectively and with an effectiveness of $91.6 \%$. On the other hand, in the case of higher flow velocity and at $7.5 \mathrm{~m} / \mathrm{s}$, the size has been reduced by only $14 \%$ with an effectiveness of $87.25 \%$. So, technically, this point is accepted as design point to compromise between the low pressure drop value and smaller physical size.

These two figures can be used as a guide to select the recuperator parameters based on the application requirements and in order to meet the required improvement in the overall cycle efficiency. Each value represents different design point of the recuperator cycle and the effects on the power output and overall efficiency of both engines are shown in the figures 12 and 13.The power output of both engines is increasing as the recuperator size increases as a result of pressure drop reduction. Moreover and as the flow velocity decreases, the high heat effectiveness values at larger recuperator size result in a lower fuel flow requirement. Furthermore, at very high flow velocity and small recuperator size, there is a change in the fuel flow trend in which it starts to decrease slightly. This is basically due to the greater associated pressure drop in both recuperator sides which in turn yields to higher reduction in the rated power as illustrated in the same figures.

The significant drop in the rated power as the recuperator flow velocity approaches $25 \mathrm{~m} / \mathrm{s}$ is affected by the low inlet turbine pressure due to the high induced pressure drop through the heat exchanger tubes. This leads to lower turbine expansion rate and in consequence a higher discharge turbine temperature. The inlet shell temperature is increasing as the recuperator flow velocity and pressure drop raise.

\section{Hot and Cold Stream Velocity $(\mathrm{m} / \mathrm{s})$}

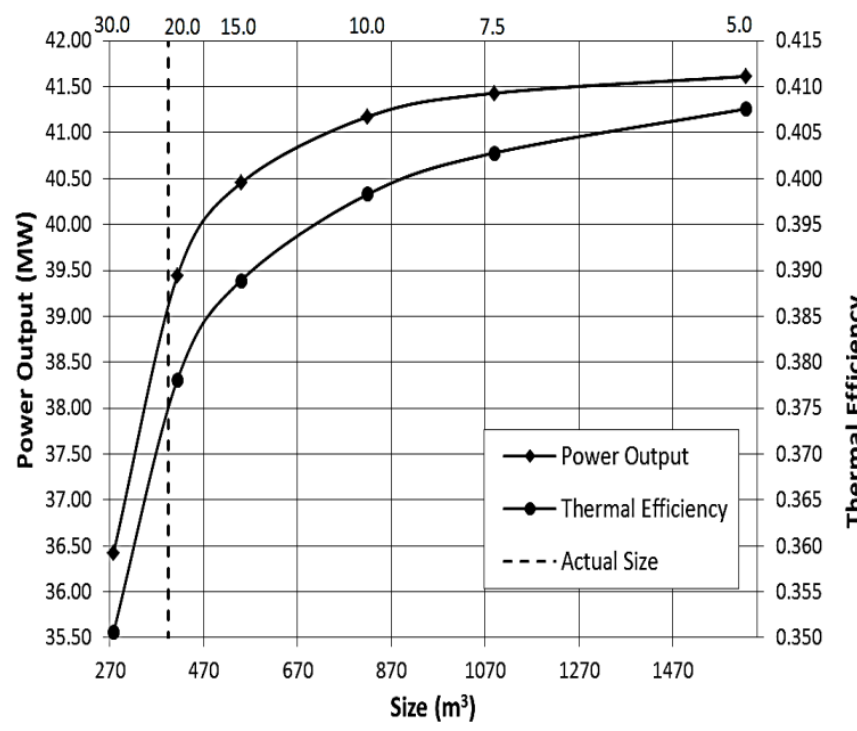

Figure 1: Influence of Recuperator Size on the Power Output and Efficiency of W6BRC 


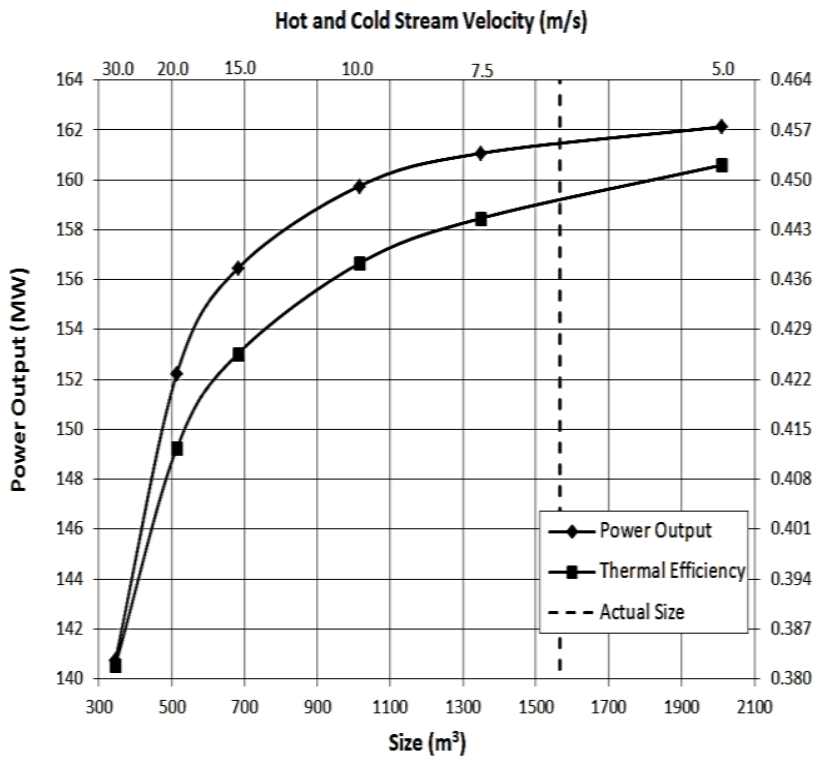

Figure 2: Influence of Recuperator Size on the Power Output and Efficiency of W 7FARC

However, the low heat transfer effectiveness between the recuperator streams at high velocity region normally overcomes the high inlet temperatures of the shell flow yielding to lower tubes discharge temperatures and higher required amount of fuel in the combustor.

On the other hand and as the recuperator flow velocity increases further, the effect of high inlet hot-stream temperature starts becoming the dominant factor against low effectiveness values.Hence, the air enters the combustor at relatively greater temperatures which accordingly reduces the required fuel flow. Regarding to the rated power, the lower turbine expansion rate as the inlet turbine pressure decreases and the recuperator flow velocity increases causing a continuous drop in the power output.

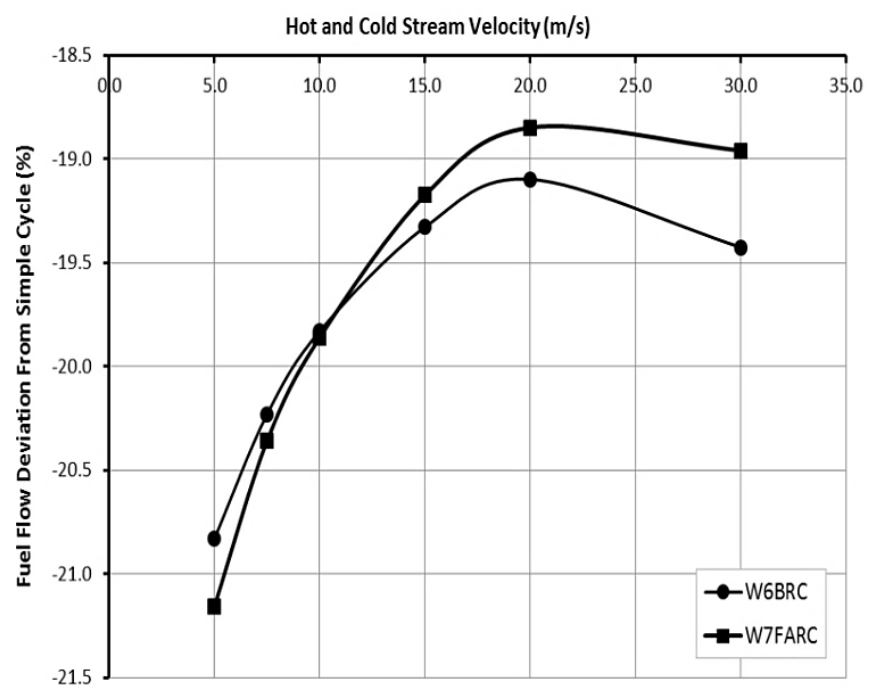

Figure 14: Influence of Flow Velocity of Recuperator Streams on the Overall Cycle Fuel Flow at Full Load Operation
Besides, the lower fuel flow at very high flow velocity leads to relatively a lower in let turbine flow which can considered as a contribution factor causing a further drop in the power output. An interesting observation was that the thermal efficiency is improving continuously with the recuperator size increase despite the reduction in the fuel flow at high flow region. In fact, this can be explained by considering the slope of the power change curve comparing with the fuel flow variation trend which shows that the reduction in power output is accelerating faster than the fuel flow drop.

\section{EFFECT OF PART-LOAD OPERATION}

By applying the recuperation, the fuel flow of $\mathrm{W} 6 \mathrm{~B}$ has been reduced by $21.2 \%$ with $7.47 \%$ increase in its thermal efficiency. Besides, the fuel flow of the engine W7FARC is lower than that of the simple cycle by $19.42 \%$ with $7 \%$ improvement in the thermal efficiency.

However, the power output of the engines W6B and W7FA have been decreased by about $3.2 \%$ and $4.1 \%$ respectively which in turn leads to reduce the specific work slightly. Besides, although there is a drop in the rated power, the thermal efficiency increased significantly due to the higher reduction in fuel flow comparing with the power output drop.

Based on the fuel flow, Figure 15demonstrates that the reduction in the fuel flow due to the use of recuperation began at $42 \%$ FL. However, the deviation between the fuel flow of simple and recuperative cycles is increasing significantly as the turbine load goes up.

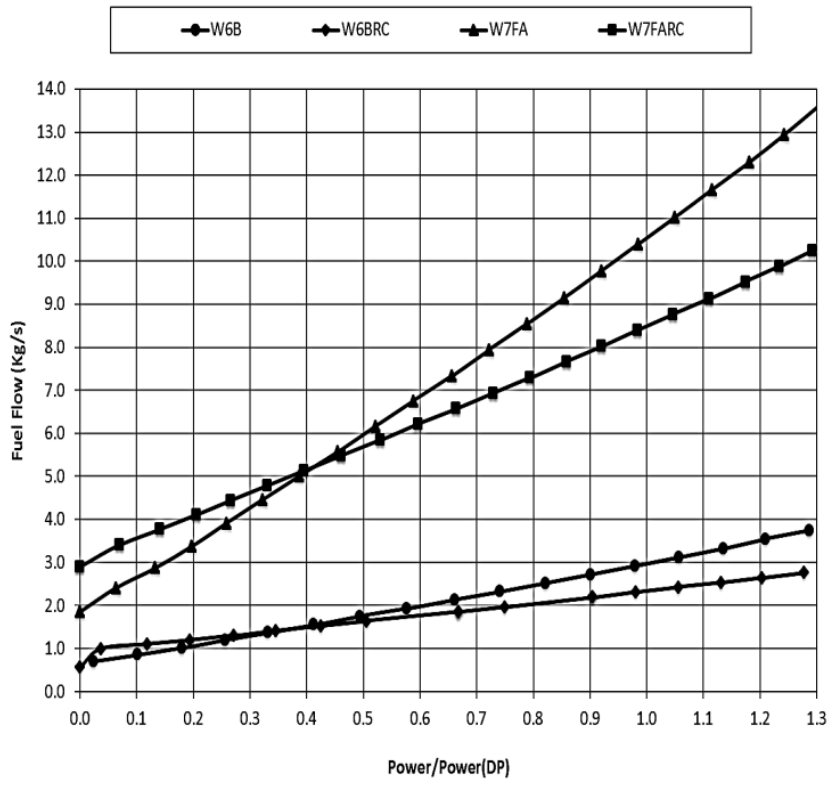

Figure 15: Fuel Flow at Part-Load Conditions of Recuperative and Simple Cycles using TET Control at ISO Conditions 


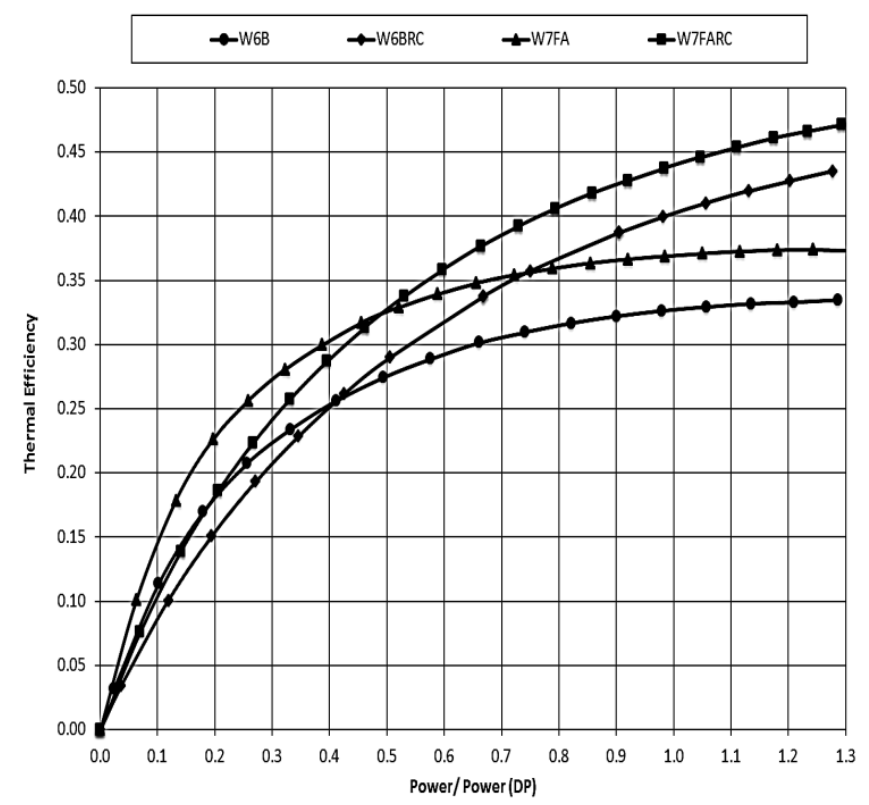

Figure 16: Thermal Efficiency at Part-Load Conditions of Recuperative and Simple Cycles using TET Control at ISO Conditions

Figure 16 illustrates the changes in the thermal efficiency of the recuperative cycle at ISO conditions during part-load operation. In the case of W6B gas turbine, the recuperative cycle is not recommended at operating load lower than $42 \% \mathrm{FL}$. Operating the engine at part load lower than this value will cause the recuperative cycle to be less efficient than the simple cycle due to the reverse heat transfer from the compressor discharge air to the turbine exhaust gas.

The difference in temperature between the two streams can be identified from figure 6 in which the difference becomes negative at lower than $42 \% \mathrm{FL}$ operation. However, W7FARC has a higher thermal efficiency than W7FA when the turbine load exceeds $45 \%$ of its full load capability in which the temperature of the exhaust gas will be greater than that of compressor discharge air. As the compression pressure ratio increases with the load rise, the use of recuperation will be more efficient and useful as a result of the increase in exhausted gas temperature so that more heat can be absorbed to heat the compressor discharge air.

In the case W6BRC engine, the improvement in the thermal efficiency due to the use of recuperation is reaching to $5 \%$ and $7.47 \%$ at $85 \% \mathrm{FL}$ and $100 \% \mathrm{FL}$, respectively. Additionally, the difference in the thermal efficiency between the recuperative and simple cycles of the engine W7FA increased from $6 \%$ at $85 \% \mathrm{FL}$ to $7 \%$ at full load operation.

\section{CONCLUSION}

This paper introduces a new systematic analytical method to:

- Select an appropriate gas turbine among operating units in the field for a recuperator retrofit.

- Design a suitable recuperator
- Evaluate the performance range of usefulness.

It was found that there is a trade-off between some of the recuperator design features. A high effectiveness heat exchanger is larger and affects the installation spacerequired and the recuperator price. So, it is essential to find a compromise between these features based on the specified application and in order to satisfy the operation requirements. The developed approach has been tested using two gas turbines engines and the estimated cycle parameters are compared with the actual values. One of the unique features of the derived method is the fact that it depends only on the flow velocity to derive the rest of performance parameters. Besides, it can be used to evaluate the existing operating gas turbines units for higher performance achievement. However, it is important to consider the economic viability of using the recuperative cycle which will be covered in the second part of this study.This is the topic of part II of this work.

\section{ACKNOWLEDGMENTS}

The first author would like to thank Petroleum Development Oman Company and Cranfield University for supporting this study.

\section{NOMENCLATURE}

\begin{tabular}{|c|c|}
\hline$Q$ & Amount of Heat Transfer \\
\hline$\dot{V}$ & Average Volumetric Flow Rate \\
\hline$J_{r}$ & $\begin{array}{l}\text { Correction Factor of Adverse Temperature } \\
\text { Gradient in Laminar Flow }\end{array}$ \\
\hline$J_{l}$ & Correction Factor of Baffle Leakage Effects \\
\hline$J_{b}$ & Correction Factor of Bundle Bypass Effects \\
\hline$J_{s}$ & $\begin{array}{l}\text { Correction Factor of Unequal Baffle Spacing at } \\
\text { Inlet and/or Outlet }\end{array}$ \\
\hline$v$ & Flow Velocity \\
\hline$C, a_{1}, a_{2}, a_{3}$ & Empirical Coefficients \\
\hline$F_{c}$ & Fraction of Total Tubes in Cross-flow \\
\hline$d_{t}$ & Inlet Tube Diameter \\
\hline$F$ & $\begin{array}{l}\text { Log-mean Temperature Difference Correction } \\
\text { Factor }\end{array}$ \\
\hline$U_{m}$ & Overall Heat Transfer Coefficient \\
\hline$\Delta P_{e}$ & Pressure Drop of End Zones \\
\hline$\Delta P_{c}$ & Pressure Drop of Interior Shell Cross Section \\
\hline$\Delta P_{w}$ & Pressure Drop of Shell Window \\
\hline$w$ & Recuperator Weight \\
\hline$J_{c}$ & Segmental Baffle W indow Correction Factor \\
\hline$h_{o}$ & Shell Heat Transfer Coefficient \\
\hline$C_{P}$ & Specific Heat \\
\hline$k$ & Thermal Conductivity \\
\hline
\end{tabular}




$\begin{array}{ll}h_{i} & \text { Tube Heat Transfer Coefficient } \\ l_{t} & \text { Tube Length } \\ D_{t} & \text { Tube Outside Diameter } \\ \mu & \text { Viscosity } \\ \varepsilon & \text { Effectiveness }\end{array}$

\section{ABBREVIATIONS}

$\begin{array}{ll}\text { CDT } & \text { Compressor Discharge Temperature } \\ \text { EGT } & \text { Exhaust Gas Temperature } \\ \text { FL } & \text { Full Load } \\ \text { GT } & \text { Gas Turbine } \\ \text { HX } & \text { Heat Exchanger } \\ \text { LMTD } & \text { Log Mean Temperature Difference } \\ \text { NTU } & \text { Number of Transfer Units } \\ \text { NPV } & \text { Net Present Value } \\ \text { OEM } & \text { Original Equipment Manufacture } \\ \text { PS } & \text { Physical Size } \\ \text { P } & \text { Power Output } \\ \text { PR } & \text { Pressure Ratio } \\ \text { RC } & \text { Recuperative Cycle } \\ \text { SC } & \text { Simple Cycle } \\ \text { TET } & \text { Turbine Entry Temperature }\end{array}$

\section{SUBSCRIPTS}

$\begin{array}{ll}\mathrm{c} & \text { Cold Stream } \\ \mathrm{h} & \text { Hot Stream } \\ 1 & \text { Inlet of Recuperator Stream } \\ 2 & \text { Outlet of Recuperator Stream } \\ \mathrm{s} & \text { Shell Side } \\ \mathrm{t} & \text { Tube Side } \\ \mathrm{Co} & \text { Compressor } \\ \text { Tu } & \text { Turbine } \\ C C & \text { Combustion Chamber } \\ a c t & \text { Actual } \\ \text { Max } & \text { Maximum }\end{array}$

\section{REFERENCES}

[1]. M. M. Rahman, Thamir K. Ibrahim, M. Y. Taib, M. M. Noor and Rosli A. Bakar (2010), Thermal Analysis of Open-Cycle Regenerator Gas- Turbine Power-Plant, World Academy of Science, Engineering and Technology.

[2]. B. Sunden and M. Faghri, (1998), Computer Simulations in Compact Heat Exchangers, Computational Mechanics Publications, Southampton.

[3]. Crane Company (1988), Flow of fluids through valves, fittings and pipe, Technical Paper No. 410 (TP 410)

[4]. Pastor, F. A. (2007), Study and Development of an Algorithm for the Transient Performance Response of a Heat Exchanger Recuperator, MSc thesis, Cranfield University.

[5]. Ierardi J. (2001), Physical and Thermal Properties of Air and Water Vapour Dependent on Temperature, Specific heat of air vs. te mperature Plot.

[6]. Prabhata K. Swamee and Akalank K. Jain (1976), Explicit Equations for Pipe-Flow Problems, Journal of the Hydraulics Division (ASCE), Vol.102, No.5, pp.657-664, India.

[7]. K. J. Bell (1963), Final Report of the Cooperative Research Program on Shell and TubeHeat Exchangers. University of Delaware Eng. Exp. Sta. Bull, USA.

[8]. H. I. H. Saravanamuttoo, G.F.C. Rogers and H. Cohen (2001), Gas Turbine Theory, 5th edition, England. 